\title{
Attitudes of Nursing and Medical Students towards Patient Care on Psychiatric Ward During Clinical Rotation at Mbarara Regional Referral Hospital.
}

\author{
Angella Namulema ${ }^{a}$ \\ ${ }^{a}$ Department of Nursing, Faculty of Medicine, Mbarara University of Science and Technology
}

Abstract

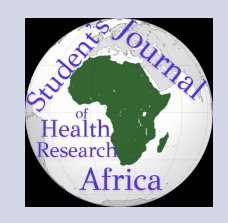

Background: ${ }^{a}$

During psychiatry, clinical rotation, nursing, and medical students care for mentally ill patients who have abnormal thoughts, behaviors, perceptions, and relationships with others is important. This makes patient care on the psychiatric ward very special and the attitudes towards patient care on the ward very key to providing quality care.

Methodology:

A qualitative descriptive design was employed. The study involved 9 fourth-year nursing students and 4 fifth and 2 fourth-year medical students who were selected by purposive sampling. Data were collected using face-to-face semi-structured in-depth interviews and analyzed using thematic analysis.

Results:

Three themes emerged from 12 categories describing attitudes of nursing and medical students towards patient care on the psychiatric ward during clinical rotation. The emergent themes were positive attitudes, negative attitudes, and uncertainty of attitudes.

Conclusion:

In conclusion, these qualitative findings suggest that nursing and medical students held both positive and negative attitudes towards patient care on the psychiatric ward during clinical rotation. In some participants the attitudes were uncertain.

\footnotetext{
${ }^{a}$ Email: angelnamulema@gmail.com

Received: 1st/02/2021 Accepted:

5th/02/2021 Journal of Community

Health and Behavioural Sciences
}

\section{Background:}

Psychiatry clinical rotations are clerkships where students can utilize the knowledge they gained in their past two years in the classroom and apply it to real clinical conditions (Roberts et al., 2009). This period is mandatory as part of the training.
Therefore, students are prepared to interface with patients through the provision of psychiatry knowledge, seminars, and case presentations among others (lyons, 2014). During clinical rotations, students receive supervisors, clinical instructors, and timely feedback. These are essential factors that con- 
tribute to the learning environment and enables students to gain competencies and experiences (Kroning, 2016). Preparation time before a psychiatry clinical rotation is very crucial in nursing and medical student's life because it is at this time that attitudes can easily be influenced (Poreddi et al., 2015). Universities have different settings, course content, expectations, teaching strategies, and duration allocated on the ward. Therefore, the clinical rotation process varies according to the university (El-Gilany et al., 2010). During psychiatry, clinical rotation nursing and medical students care for the mentally ill patients who have abnormal thoughts, behaviors, perceptions, and relationships with others (Oud et al., 2009). This makes patient care on psychiatric ward very special and the attitudes towards patient care on this ward very key to providing quality care (Dawood et al., 2012). Attitude is a psychological tendency that is expressed by evaluating an entity with some degree of favor or disfavor (Eagly et al., 2007), attitude is a readiness to react to an object in a certain way. Attitudes aren't directly dependent on knowledge. Knowledge might change one's opinion but might not change their attitude (Suwalska et al., 2017). The attitudes of nursing and medical students towards patient care vary from favorable to unfavorable (Konzelman, 2017). Studies reported that nursing and medical students hold negatives attitudes towards patient care in the psychiatric ward (Dawood et al., 2012, Kroning 2016 \& Kareem et al., 2020). According to Dawood et al., (2012), it is reported that there is an education gap in nursing and medical psychiatry whereby students are ill-prepared for the clinical rotation, lack supervisors, have limited instructor-student interaction, and lack role models in the clinical area (Dawood et al., 2012, Hastings 2015 \& Konzelman 2017). The latter could have contributed to the negative attitudes. However, limited studies have been done on attitudes of nursing and medical students towards patient care on a psychiatric ward in resource-limited countries and study area inclusive. Therefore, this study aimed at exploring nursing and medical students' attitudes towards patient care on the psychiatric ward during clinical rotation.

Globally, studies have revealed that nursing and medical students hold negative attitudes towards patient care on the psychiatric ward during clinical rotation (Kroning, 2016). However, most studies report that these negatives attitudes are held espe- cially before clinical rotation and can be influenced by providing good clinical instructors and supervision (Dawood et al., 2012 \& Kareem et al., 2020). These negative attitudes especially among nursing and medical students contribute to poor healthseeking behavior among patients and adversely affect treatment outcomes.

In Africa, a study by Hailesilassie et al., (2017) found that students had a positive attitude towards patient care on the psychiatric ward before rotation. This was related to the fact that these students hadn't encountered violent patients or the clinical environment which could have influenced their attitude. Another study in South Africa by Witt et al., (2019) reported that female students had more positive attitudes towards patient care on the psychiatric ward than male students because they were more empathetic than male students. However, a study by Iheanacho and colleagues found out that nursing and medical students had negative attitudes towards patient care on the psychiatric ward and the attitudes were informed and reinforced by cultural, traditional, and religious beliefs about the causes of mental illness (Iheanacho et al., 2014).

Psychiatric clinical rotation is essential in the preparation of students to gain competencies to be better nurses and doctors (Dawood et al., 2012). However, in Uganda and the study area, there is a paucity of information about the attitudes of nursing and medical students towards patients on the psychiatric ward during clinical rotation.

All nursing and medical students are mandated to rotate on psychiatric wards and care for mentally ill patients as a pre-requisite for their undergraduate program (Shammari et al., 2020). During clinical preparation, students are provided with adequate psychiatry knowledge and assessed to ensure that they are ready for rotation and are supervised. They are instructed by trained clinical instructors who give them all the necessary support they need which relieves students' anxiety and promotes a good learning environment.

However, most nursing and medical students end up rotating on the psychiatric ward when they aren't psychologically prepared about the impact of their attitudes towards patient care and the possible treatment outcomes. Also, during the researcher's clinical rotation on a psychiatric ward, she observed that students were anxious when caring for patients and had limited interactions with 
their supervisors. Adequate clinical rotation preparation and increased interaction between supervisors can reduce unfavorable attitudes. There is a paucity of information regarding the attitudes of nursing and medical students towards patient care on psychiatric wards during a clinical rotation in the study area.

\section{METHODOLOGY}

\section{Area of study}

This study was conducted at Mbarara University of Science and Technology which is located in the Southwestern region of Uganda. It's located along the Mbarara-Kabale Highway approximately 267 kilometers from Kampala along Kampala-Kabale Highway in Mbarara city. MUST has four faculties and of which faculty of medicine is one of them. The faculty of medicine has six different disciplines and these include Bachelor of Medicine and Surgery, Bachelor of Nursing Science, Bachelor of Physiotherapy, Bachelor of Pharmacy, BacheIor of Medical Laboratory Science, and Bachelor of Pharmaceutical Science. Nursing and medical students were chosen from the faculty of medicine because they have a mandatory clinical rotation on all wards in MRRH, psychiatry ward inclusive.

\section{Study design.}

A qualitative descriptive cross-sectional study design was employed. According to Polit and Beck, (2012) descriptive studies present comprehensive summaries of a phenomenon in everyday language and a cross-sectional study design involves the collection of data at one point in time. This design was chosen for the reason that it is less time consuming than quantitative experiments, effective to analyze non-quantified topics, and explains and describes the phenomenon (Burns \& Grove, 2003).

\section{Study population.}

Fourth-year nursing and fourth/fifth-year medical undergraduate students at MUST, this population was chosen because they studied about mental illness and rotated on the psychiatric ward of MRRH.

\section{Sampling method}

A purposive sampling method was employed to recruit the study participants for the study. This method is chosen because participants will provide in-depth information about the phenomenon under investigation (Steuber \& Carpenter, 2011).

\section{Sample size determination}

The sample size that was used in the study was 15 participants. According to Polit and Beck (2012), a sample size of 6-12 participants is sufficient as the emphasis is put on the richness of the data collected and not on the number of study participants. The sample size for this study was determined by redundancy whereby no new information was extracted from participants.

\section{Inclusion criteria}

The study included all the nursing and medical undergraduate students who have rotated on a psychiatric ward in the year 2018/2019 and who consented to participate in the study.

\section{Exclusion criteria}

Students who were not around MUST during data collection.

Students who were sick at the time of data collection.

\section{Pilot study}

A pilot study was conducted. The pilot study was conducted at MUST where only 3 nursing completion students participated. The pilot study tested the proposed study design and process and alerted the researcher about issues that might have negatively affected the research and was corrected based on the feedback from the pilot study. This study also helped the researcher gain some important skills in data collection.

\section{Data Collection Tool}

Data was collected using a self-report semistructured interview guide with open-ended questions which allowed participants to respond to questions in their own words. The interview guide ensures that all question areas are covered (Polit and Beck, 2012). The tool was developed based on a literature review and guided by the supervisor to fit in the study. 


\section{Data collection procedure}

Data was collected using semi-structured interview guides with open-ended questions related to the study and probing questions were used for clarity. This technique gives respondents the freedom to respond in their own words, provide as much detail as they wish, and offer explanations (Polit \& Beck, 2012). Permission was sought from participants to use an audio recorder during the interview. This enabled the researcher to capture the participant's response in addition to notes that were taken. This helps the researcher to minimize recall bias during data analysis, and to also pay more attention to the participant's nonverbal communication. The data collection was conducted in the hostels and places suggested by participants according to their choices.

\section{Data Analysis}

This was done using thematic qualitative analysis. The method was chosen because it was easy and quick for a new qualitative researcher. The thematic analysis allows a detailed description of a particular theme within the data (McCusker et al., 2011). It consisted of six steps as below;

The researcher familiarized herself with the data: where she got immersed in the data by reading and re-reading textual data and listening to audio recordings.

Researcher generated initial codes: this begun the systemic analysis of the data. Codes are building blocks of analysis. Codes were identified and provided a label for a feature of the data that was potentially relevant to the research question.

The researcher searched for themes: the theme captured something about the data about the research question and represented some level of preferred response within the data set.

The researcher reviewed potential themes: the developed themes were reviewed about the coded data and entire data set.

The researcher defined and renamed themes: researcher was able to clearly state what was unique and specific about each theme

The researcher produced the report: the report provided a compelling story about the data based on data analysis. The story was convincing and clear, yet complex and embedded in a scholarly field.

\section{Rigors of research or \\ trustworthiness}

The rigors of research were attained by ensuring trustworthiness. To enhance trustworthiness, Guba and Lincoln (1985) suggested four criteria for qualitative research and these include credibility, transferability, dependability, and conformability.

\section{Credibility}

This criterion is described as the confidence in the truth of findings as judged by participants and others (Polit\& Beck, 2006). Credibility was achieved by using a purposive sampling method, stuck to the inclusion criteria, pretested the data collection tool, and prolonged engagement by having sufficient time during the interviews.

\section{Dependability}

According to Polit \& Beck, (2006), dependability refers to the stability of data over time and conditions. It establishes the research study's findings as consistent and repeatable. Dependability was achieved by having an outside researcher who examined data collection, data analysis, and the results of the research study.

\section{Conformability:}

According to Polit\& Beck (2006), conformability refers to the potential for congruence between two or more independent people about the data's accuracy, relevance, or meaning. This criterion is concerned with establishing that the data represent the information participants provided and that the interpretation of those data isn't figments of the inquirer's imagination. This was achieved by including narrative quotes in my final study findings.

\section{Transferability}

According to Lincoln and Guba (1985), transferability is defined as the extent to which findings can be transferred to other settings. This was achieved through the thick description of the setting and participants provided a detailed portrait of the setting in which the research was conducted. The intention was to give readers enough information for them to judge the applicability of the study findings to other settings. Transferability was attained by allowing each study participant to tell his or her 
independent attitudes towards patient care during psychiatry clinical rotation exhaustively until no new information was aired out.

\section{Ethical consideration}

The researcher got an introductory letter from the Department of Nursing at MUST. The proposal was submitted to the Faculty research committee for approval. Permission was sought from the gatekeeper and gained access to the participants. The study was fully explained to those who met the inclusion criteria and informed consent was obtained from the participants seeking permission before involving them in the study. Participants were assured that participation is voluntary and that they were free to withdraw at any time they felt like. Participants were issued codes to ensure confidentiality. The researcher kept the completed interview recordings on a phone with a passcode only known to her and ensured privacy and confidentiality.

\section{Dissemination of results}

The study findings were presented in form of a written dissertation and a copy was submitted to the library in the Department of Nursing at MUST on 19th December 2020. A copy was prepared for publication in a peer-reviewed journal.

\section{Results and Discussions Demographic characteristics of the partici- pants}

The study involved 15 participants of whom 9 were fourth-year nursing students, 2 were the fourth year and 4 were the fifth year medical students of MUST. Males students dominated the study (10) and 5 were females. The mean age of the participants was 23.9 years.

\section{Table 1: Themes and Categories}

\subsection{Theme 1: Positive attitudes}

This theme emerged from four categories namely; empathy towards patients, understanding and patience towards patients enjoyed the patients and adequate clinical support as indicated in table 3 below.

Category 1: empathy towards patients
Participants described that they felt pity, empathy, and sorry for the patients, and some got attached to these patients as noted in the excerpts below.

.." I felt touched by these patients I felt like I could do something for this patients and I got attached to some patients...." (5).

.." I could feel empathetic for these patients sometimes while caring for them, I could feel pity for those patients" $(9,14)$.

Category 2: Understanding and patience towards patients

Participants noted that caring for mentally ill patients needs patience and understanding as noted in the excerpts

..." when caring for mentally ill patients you just have to understand, be patient, and listen to all they have to say" $(14,12)$.

.." I learned that managing psych patients need patience, you need to understand their situation to handle them" (11).

\section{Category 3: Enjoyed the patients}

Participants described that they enjoyed caring for the patients because they were fun, could make jokes, and had interesting stories as depicted in the response below;

.."I think I enjoyed, those people are fun, yeah it is some interesting part of medicine, those people it's like something went wrong with their brain and they act normal and then you're amazed by the way they do things"..(2, 3).

\section{Category 4: Adequate clinical support}

Participants noted that the staff on the ward were welcoming, friendly, good, and could teach them, allow them to care for a patient and this provided a good learning environment for them as noted in the excerpts below.

.." The staffs there are friendly; they would encourage us more to learn. They would provide a good learning environment. The clinical officer could give us assignments and ask us questions" $(3,5)$

..." with the clinical officer, he was very open and he would teach us like a group and give us detailed work and even allow you to clerk a patient in his presence" (5).

\section{Theme 2: Negative attitudes}

This theme emerged from four categories namely: scared of the patients, judgment towards patients, fear of approaching violent patients, and lack of clinical supervision as indicated in table 4 below. 
Table 1. Themes and Categories

\begin{tabular}{ll}
\hline Themes & Categories \\
Positive attitudes & Empathy towards patients Understanding and \\
& patience towards patients Enjoyed the patients \\
Negative attitudes & Adequate clinical support \\
& Scared of the patients Judgmental towards pa- \\
& tients Fear of approaching violent patients Lack \\
Uncertainty of attitudes & of clinical supervision \\
& Pre-conceived ideas towards mental illness Fear \\
& of contracting mental illness Mentally ill patients \\
& are unpredictable Lack of psychiatry clinical \\
& preparation \\
\hline
\end{tabular}

Table 2. Positive attitude

\begin{tabular}{ll}
\hline Themes & Categories \\
Positive attitudes & Empathy towards patients Understanding and patience towards pa- \\
& tients Enjoyed the patients Adequate clinical support \\
Negative attitudes & Scared of the patients Judgmental towards patients Fear of approach- \\
& ing violent patients Lack of clinical supervision \\
Uncertainty of attitudes & Pre-conceived ideas towards mental illness Fear of contracting mental \\
& illness Mentally ill patients are unpredictable Lack of psychiatry clinical \\
& preparation
\end{tabular}

Table 3. Negative attitudes

\begin{tabular}{ll}
\hline Themes & Categories \\
Positive attitudes & Empathy towards patients Understanding and pa- \\
& tient towards patients Enjoyed the patients Ade- \\
quate clinical support & Scared of the patients Judgmental towards pa- \\
Negative attitudes & tients Fear of approaching violent patients Lack \\
& of clinical supervision \\
Uncertainty of attitudes & $\begin{array}{l}\text { Pre-conceived ideas towards mental illness Fear } \\
\text { of contracting mental illness Mentally ill patients } \\
\text { are unpredictable Lack of psychiatry clinical prepa- } \\
\text { ration }\end{array}$ \\
\hline
\end{tabular}

\section{Category 1: scared of the patients}

Participants noted that they were scared of the mentally ill patients especially the violent and aggressive ones as noted below;

" maybe the problem is the patients hahaha because the patients, of course, there is that way, they are scary". $(1,8,4)$

..." those patients are very aggressive so you find you are going to manage a patient while the patient wants to grab you and kill you, I was scared of them so it required taking great care with myself" (12) ...

\section{Category 2: Judgmental toward patients}

Participants described that they had judgments towards mentally ill patients especially the substance abusers and that they were responsible for their mental illness and they always blamed them as depicted in the responses below;

.." I don't usually judge but I think some patients are somehow responsible for their mental illnesses like people who read and read and they run mad hahaha" (3) 
..." when it came to the substance abusers, I was too judgmental towards them, I was blaming them because you find someone is psychotic and the reason is overdependence on what, alcohol and those other drugs of dependence" $(15,14) \ldots$...

Category 3: Fear of approaching violent patients

Participants noted that they were always afraid of approaching violent or aggressive patients and they consequently avoided attending to them as mentioned in the excerpts;

"There was an arrogant and violent patient I was told to sedate but I couldn't because I feared him, I just told the intern nurse to help and I assisted" $(5,3)$.

"I had bias when it came to choosing a patient; I didn't attend to those hyper-violent patients because I was afraid of what they could do" (15)

\section{Category 4: Lack of clinical supervision}

Participants noted that they weren't supervised and given any feedback in the clinical area, so they felt unguided on the ward as noted in the excerpts below;

"supervision! If you are talking about the lecturers who are meant to supervise us, we were never supervised" $(4,13)$.

"We didn't interact with the supervisors so we weren't guided on the ward so we didn't know what to do on the ward" (3).

"actually to be flank, yeah, I didn't receive any feedback from all the write-ups we made, there was no feedback, she just said she will use them as an assessment tool," $(2,1,13)$.

\section{Theme three: uncertainty of attitudes}

This theme emerged from four categories namely; preconceived ideas about mental illness, fear of contracting the mental illness, unpredictable patients, and lack of psychiatry clinical preparation as indicated in table 5 below.

\section{Category 1: Preconceived ideas about men-} tal illness

Participants noted that while on rotation they had preconceived ideas about mental illness which made them have a wrong image about mentally ill patients at the start as claimed below;

" Before I came I thought I would find people trying to throw stones, maybe people fighting to my surprise they were calm people, maybe a little talkative but they were just one or two. Aggressive patients but they were still managed with diazepam"(6, 14).

Category 2: Fear of contracting the mental illness
Participants described that they had a fear that they would contract a mental illness while taking care of mental patients as depicted in the response below;

"I used to fear that caring for mentally ill patients can trigger mental illness to manifest in me if I had a gene for mental illness" $(4,7,5)$

I believe $50 \%$ that mental illness is because of witchcraft, I was a bit scared, I could fear that maybe the charm could get me and also I become mentally ill "(8)

Category 3: Mentally ill patients are unpredictable

Participants noted that the behaviour of mentally ill patients is unpredictable and it couldn't be tolerated as noted below;

"mmmm I can't tolerate them because they are unpredictable, fine some of them have nice stories but then some are too violent for life" (2).

Category 4: Lack of psychiatry clinical preparation

Participants noted that they were not psychologically prepared, had limited knowledge, and didn't have enough skills to attend to mentally ill patients as indicated below;

“Mmmh like knowledge-wise my lecturer didn't do much Yeah for her what she concentrated on is these things of theories laws but ignoring the actual psychiatry, so you could feel intimidated" (5).

"I wasn't prepared in any way. We were the first group to rotate there and it was at the beginning of the semester. I wasn't prepared psychologically by the lecturer."(13)

"I remember when I rotated there I had little knowledge concerning psychiatric disorders, so that was some kind of negative attitudes and I would be there trying to figure out a condition I couldn't so I wasn't able to deliver the care necessary"(15).

\section{Summary of chapter four}

The research findings revealed three themes emerging as; positive attitudes, negative attitudes, and uncertainty of attitude. Each theme emerged from four categories hence a total of twelve categories. Positive attitudes emerged from empathy towards patients, adequate clinical support, understanding, and patience towards patients, and enjoyed the patients. Negative attitudes emerged from judgmental towards patients, scared of the patients, fear of approaching violent patients, and lack of clinical supervision. Uncertainty of attitudes emerged from fear of contracting the men- 
Table 4. Uncertainty of attitudes

\begin{tabular}{|c|c|}
\hline Themes & Categories \\
\hline Positive attitudes & $\begin{array}{l}\text { Empathy towards patients Understanding and patient towards patients Enjoyed the } \\
\text { patients Adequate clinical support }\end{array}$ \\
\hline Negative attitudes & $\begin{array}{l}\text { Scared of the patients Judgmental towards patients Fear of approaching violent patients } \\
\text { Lack of clinical supervision }\end{array}$ \\
\hline $\begin{array}{l}\text { Uncertainty of atti- } \\
\text { tudes }\end{array}$ & $\begin{array}{l}\text { Pre-conceived ideas towards mental illness Fear of contracting mental illness Mentally } \\
\text { ill patients are unpredictable Lack of psychiatry clinical preparation }\end{array}$ \\
\hline
\end{tabular}

tal illness; mentally ill patients are unpredictable, pre-conceived ideas, and lack of psychiatry clinical preparation.

\section{DISCUSSION}

\section{Positive attitudes}

The study revealed that both male and female students had positive attitudes towards patient care in a psychiatric ward. They always felt sorry, touched, empathic, pity for these patients and felt like they could do something more to help them. However, the study finding disagrees with research by Hailesilassie et al., (2017) which reported that females were more empathetic than males. Since the participants' mean age is 23.9 years the later study finding is in agreement with three different studies conducted in South Africa, Ethiopia, and Egypt (Witt et al., 2019, Hailesilassie et al., 2017; ElGilany et al., 2010) respectively which showed that age affected attitudes. Younger age had a more positive attitude because they were more empathetic than older age (Witt et al., 2019; Hailesilassie et al., 2017). Others were patient and understanding when caring for these patients and also said that the patients were fun, interesting, and they enjoyed caring for them. This could be attributed to the good, welcoming, friendly clinical instructors who could teach and support the students during patient care. The finding correlates with a study by Lin Hor et al., (2020) who reported that direct contact with patients, support by an enthusiastic psychiatric faculty, on-site learning experiences in hospitals, and the joy of being able to help a patient impacted students' attitudes positively.

\section{Negative attitudes towards patient care}

The research demonstrated that students had different negative attitudes towards mentally ill patients as they were scared of them, avoided attending to them, blamed them, and said that they were responsible for their mental conditions. The research finding is in agreement with studies (Kroning, 2016, El-Din et al., 2016, Kareem et al., 2020 \& Hunter et al., 2014) that found that medical and nursing students hold negative attitudes towards patient care during psychiatry clinical rotation. This could have been due to lack of clinical supervision as most students said they were never given feedback on their assignments or even supervised in the clinical area and consequently felt unguided on what to do for the patients. The finding disagrees with studies by (Dawood et al., 2012, Desai et al., 2018 and Lin Hor et al., 2020) which report that clinical rotation impacted students' attitudes positively.

\section{Uncertainty of attitude outcome}

This research noted that the attitudes of students were ambivalent, changeable, unforeseeable, and unpredictable as most students reported being scared at the start of rotation and later got used to the patients. Most of the students feared contracting mental illness because of the cultural beliefs they had and preconceived ideas of how mentally ill patients could be like which were informed by the communities they lived in. This finding is similar to a study by Iheanacho et al., (2014) who argued that the fear in nursing and medical students towards mental illness is informed and reinforced by traditional, cultural, and religious beliefs in their communities. Other students reported that patients were unpredictable, and they couldn't tolerate their behaviors. This can be attributed to a lack of psychiatry clinical preparation as most students said they weren't prepared in any way and had limited knowledge about mental disorders. The finding was supported by Kroning (2016) who reported that students always felt unprepared and consequently perceived that psychiatry is challenging. 


\section{Conclusion}

The study reveals the attitudes of nursing and medical students towards patient care in psychiatric wards during clinical rotation. The attitudes of students were positive, negative, and uncertain. Positive attitudes were impacted by fun and interesting patients, the feeling of helping these patients, and welcoming clinical instructors who could teach and support the students. While negative attitudes students held were due to lack of adequate clinical supervision and the nature of patients who were aggressive, violent, and arrogant. On the other hand, student's attitudes were uncertain due to lack of psychiatry clinical preparation.

\section{Limitations of the study}

The study was conducted during the COVID19 pandemic lockdown where participants were not easily accessed. It represented only a small number of nursing and medical students, and the attitudes that were uncovered may not necessarily ascribe to other nursing and medical students. While qualitative phenomenology is not intended to be generalized to a broad group it is hoped that the responses of participants will be powerful and add to the body of work regarding the attitudes of nursing and medical students towards patient care on the psychiatric ward during clinical

Rotation.

\section{Implications of the study \\ Clinical practice}

Students' attitudes while attending to patients on specific hospital units affects the quality of care they give to those patients.

\section{Policy}

This study informs the benefits of adequate clinical support on the psychiatric unit of MRRH.

\section{Education}

Practice on the units is based on theoretical aspects to be taught in the curriculum.

\section{Recommendation}

There is a need for better psychiatry clinical preparation of students before clinical rotation. This calls for professional nursing and medical lectures, equipped skills laboratory, and a wellequipped library.

\section{Areas of further research}

- Since students are mentored by the staff on the mental health unit, a similar study should be done to find out the attitudes of the mental health unit staff while attending to patients on the psychiatric unit

- Similar studies should be done in other universities in the country and the results compared will help in a better understanding of students' attitudes towards patient care on a psychiatric ward.

- Another study should be carried out on the factors that influence students' attitudes while caring for mentally ill patients.

\section{Acknowledgement.}

I give honor to the almighty GOD for giving me the strength, grace, wisdom, patience, and understanding that made me able to accomplish this task.

I send my sincere appreciation to the MUST department of nursing and my supervisor Dr. Grace Nambozi for the guidance, encouragement, and educational advice throughout the study.

I also send my sincere gratitude to the MUST Dean of students who granted me the opportunity to collect data from the nursing students but not forgetting all the nursing and medical students who participated voluntarily in this study.

Pray the almighty God to reward all of you abundantly

\section{LIST OF ABBREVIATIONS}

BNS Bachelor of Nursing Science

DON Department of nursing

FOM Faculty of medicine

HPCs Health care professionals

MRRH Mbarara Regional Referral Hospital

MUST Mbarara University of Science and Technology

WHO World Health Organization

\section{LIST OF DEFINITIONS}

Mental illness: Mental illness is a clinically significant condition generally characterized by a combination of abnormal thoughts, perceptions, emotions, behavior, and relationships with others (Oud et al., 2009).

Attitude: Attitude is a psychological tendency that is expressed by evaluating an entity with some degree of favor or disfavor.

Psychiatry clinical rotation: This is a period where nursing and medical students attend psychiatric wards in hospitals and apply what they studied theoretically, deal with patients, and provide 
care and treatment to them under guidance and supervision.

Medical student: A student enrolled in medical school to pursue a bachelor's in medicine and surgery who is trained for five years plus one year of internship to become a medical officer (Poreddi et al., 2015).

Nursing student: A student enrolled in nursing school to pursue a bachelor of science in nursing after her post-secondary school and trained for four years plus one year of internship to become a nursing officer (Awis et al., 2012).

\section{References.}

1) Awis, A., Perera, R., Vasantha, H.L, Heregama, $T$ \& Fernando, S. (2012). The attitudes of medical students towards the mental mentally ill: the impact of a clinical attachment in psychiatry. Sri Lankan Journal of Psychiatry, 3(2), pp12-15 https://doi.org/ 10.4038/sljpsyc.v3i2.5132

2) Burns, N \& Grove, S.K (2003).The practice of nursing research: Conduct, critique and utilization. Toronto: WB Saunders.

3) Dawood, E. (2012). Impact of clinical placement on nursing students' attitudes towards Psychiatry. "Journal of American Science, 8(2), pp627632

4) Desai, D. H \& Chavda, D. P. (2018).Attitudes of undergraduate medical students towards mental illness and Psychiatry.Journal of Education and Health promotion, 7, 50. https://doi.o rg/10.4103/jehp.jehp_87_17 PMid:29693031 PMCid:PMC5903151

5) EIDin, M.A., Amen, R.G., ElChamry, H.R., Mahmoud, M.D \& Kandel, H.A. (2016).Attitudes of medical students towards mentally ill patients: Impact of a clinical psychiatric round. The Egyptian Journal of Neurology, Psychiatry and Neurosurgery, 53(1), pp6-11 https://doi.org/10.4103/1110-1083.176321

6) Gilany, E.H.A \& Amr, M. (2010).Students' Attitudes towards Psychiatry at Al-Hassa Medical College, Saudi Arabia.Academic psychiatry, 34(1), pp71-74 https://doi.org/10.1176/appi.ap.34. 1.71 PMid:20071736

7) Hailesilassie, H., Kerebih, H., Negash, A., Girma, E., Siebeck, M \& Tesfaye, M. (2017). Attitudes of Medical students towards Psychiatry: The case of Jimma university, South west Ethiopia.Journal of Health Sciences, 27(3), pp207-214. https:// doi.org/10.4314/ejhs.v27i3.2 PMid:29217919 PMCid:PMC5614991

8) Hastings, T. (2015). Nursing student attitudes towards mental illness: A quantitative Quasiexperimental study. ProQuest LLC, pp1-123

9) Hor, L.S., Russel, V., Vasudevan, U \& Brien, F. (2020).Changing attitudes to psychiatry and interest in the specialty as a career choice during clinical undergraduate years at a medical school in Penang, Malaysia.Ir Journal of Medical Science, 189(1), pp253-259. https://doi.org/10.1007/s11845019-02064-x PMid:31338691

10) Hunter, L., Weber, T., Shattel, M \& Harris, A.B. (2014).Nursing students' attitudes about psychiatric Mental health Nursing. Informa Health care, pp16 https://doi.org/10.3109/01612840.2014.935901 PMid:25397970

11) Iheanacho,T.,Stefanovics,E.,Makanjuola,V.,Merienfeld, C \& Rosenheck, R.(2014).Medical and Nursing students' attitudes to people with mental illness in Nigeria a tale of two teaching hospitals. International Psychiatry, 11(2), pp43-45 https://doi.org/10. 1192/S1749367600004380

12) Iyons, Z. (2014).Impact of the psychiatry clerkship on medical students' attitudes towards psychiatry and to psychiatry as a career.Acad Psychiatry, 38: 35-42 https://doi.org/10.1007/s40596-013-0017 -3 PMid:24464416

13) Kareem, O., Uaz, B., Masood, A., Mehmood, Y., Mussarat, K \& Riaz, J. (2020),"Attitudes of medical students Towards Psychiatry in a tertiary care Hospital. "Journal of Medicine, Physiology and Biophysic, 63, pp39-46

14) Konzelman, L. (2017).Undergraduate Nursing students' attitudes towards mental illness and mental health Nursing.Pp1-89

15) Kroning, M. (2016).Strategies for Improving Nursing students' mental Health Clinical Rotation.JCN, pp23-28.

16) McCusker, J., Cole, M.G., Voyer, P.J., Monette, J., Champoux, N \& Ciampi, A. (2011).Use of nurseobserved symptoms of delirium in long-term care: effects on prevalence and outcomes of delirium. IntPsychogeriatr, 23 (4), 602-608. https://doi.org/1 0.1017/S1041610210001900 PMid:20880428

17) Oud, J. T. M., Schilling, J., Aloof, J. C., Groenier, H. K., Decker, H.J \& Betty.(2009). Care for patients with mental illness: the general practitioner's role perspective. BMC family practice,10(1),29 https:// doi.org/10.1186/1471-2296-10-29 PMid:19419547 PMCid:PMC2685366 
18) Polit, D. F., \& Beck, C. T. (2006). Essentials of nursing research: methods, appraisal, and utilization Denise F Polit Essentials of nursing research: methods, appraisal, and utilization. 'Nurse1; 13 (4):91-92. https://doi.org/10.7748/nr.13.4.91.s11 PMid:27702222

19) Polit, D., \& Beck, C. (2012).Nursing research: Generating and assessing evidence for nursing practice, Philadelphia, PA: Wolters Kluwer.

20) Polit, D.F., \& Beck, C.T. (2010).Essentials of nursing research: Appraising evidence for Nursing Practice' 7th Edition.

21) Poreddi, V., Thimmaiah, R., \& Math, S.B. (2015).Attitudes towards people with mental illness among medical students.Journal of Neuroscience in Rural practice, 5(3), pp349-354 https://doi.org/10 .4103/0976-3147.154564 https://doi.org/10.4103/ 0976-3147.154569

22) Roberts, T.K., Robinson, M.K., Stewart, C \& Felicia, S.(2009).An integrated mental health clinical rotation. Journal of nursing education,4(8), pp454459 https://doi.org/10.3928/01484834-20090518-0 6 PMid:19681535

23) Shammari, M., Waggas, S.D \& Hasan, A.A. (2020).Assessment of nursing students' attitudes and stigma towards mental illness: A crosssectional study.Journal of Nursing education and practice, 10(9).pp1-11 https://doi.org/10.5430/jnep. v10n9p1

24) Speziale, H.S., Streubert, H.J. \& Carpenter, D.R. (2011). Qualitative Research in Nursing: Advancing the Humanistic Imperative. 5th edition Lippincotts Williams and Wilkins.

25) Sulwaslska, J., Suwalska, A., Podcszaska, N.A \& Lojko, D. (2017).Medical students and stigma of depression: Part 1 stigmatization of parents. Department of psychiatry.

26) Wit, C., Smit, F., Jordan, E., Koen, L., Niehaus, D.J.H \& Botha, U. (2019).The impact of a Psychiatry clinical rotation on the attitudes of South African final year medical students towards mental illness. BMC medical education, 19(1), 11 https://doi.org /10.1186/s12909-019-1543-9 PMid:31023368 PMCid:PMC6482575 